\section{Interleukin 16 polymorphism and susceptibility of rheumatoid arthritis disease in Egyptian population}

\author{
Shereen Mostafa ${ }^{1}$, Samah I. Nasef ${ }^{2}$, Amany M. \\ Hassan $^{3}$, Azaa M. Abdalla ${ }^{1}$ and Hanan H. Omar ${ }^{3}$ \\ ${ }^{1}$ Department of Chemistry, Faculty of Science, Suez Canal \\ University, Ismailia, Egypt. \\ ${ }^{2}$ Department of Physical Medicine and Rheumatology \& \\ Rehabilitation, Faculty of Medicine, Suez Canal University, \\ Ismailia, Egypt. \\ ${ }^{3}$ Department of Clinical Pathology, Faculty of Medicine, Suez \\ Canal University, Ismailia, Egypt.
}

The Egyptian Journal of Immunology Volume 28 (4), 2021: 282-289. www.Ejimmunology.org
Corresponding author: Hanan Hassan Omar, Department of Clinical Pathology, Faculty of Medicine, Suez- Canal University, Ismailia, Egypt.

Email: hananhassan1978@gmail.com..

\begin{abstract}
Rheumatoid arthritis (RA) is a systemic and multiple-stage disorder characterized by chronic inflammation with extensive synovitis. The genetic and environmental factors are associated with the risk for RA development. In RA, the induced IL-16 may play a role in initiating, sustaining and increasing the inflammatory response and development of synovitis, nevertheless IL-16's actual role in RA pathogenesis must be studied further. This study intended to investigate the association of IL16 gene polymorphism and RA disease, to determine the genetic role of IL-16 polymorphism and predict the risk of RA development and clinical disease activity. One hundred and Fifty RA patients and 150 apparently healthy control subjects were included in this case-control study. RA disease activity and functional status were evaluated for all RA patients. IL-16 gene polymorphism (SNP rs11556218 T/G) was genotyped using real-time polymerase chain reaction. The difference in IL-16 ( $r$ 11556218 T/G) genotype frequencies between RA patients and controls was not statistically significant. However, the $G$ allele was frequently presented in RA patients as compared to controls $(p=0.047)$. Moreover, $G$ allele carriers had two times more risk to develop RA disease than T allele carriers (OR=2.598; $95 \% \mathrm{Cl}=1.078-6.825)$ with dominant genetic association. Alternatively, the $\mathrm{G} / \mathrm{G}$ genotype was associated with high CDAI, RADAS- 5 and HAQ disability index in comparing to other genotypes (T/T-T/G). In conclusion, there was an association between allele $\mathrm{G}$ of IL-16 polymorphism ( $r$ 11556218 T/G) and risk of RA disease development. In addition, there was an association between genotype $\mathrm{G} / \mathrm{G}$ and increased clinical disease activity and health disability.
\end{abstract}

Keywords: IL-16; polymorphism; rheumatoid arthritis; disease activity; genetic model.

Date received: 23 August 2021; accepted: 29 September 2021

\section{Introduction}

Rheumatoid arthritis (RA) is a systemic and multiple-stage disorder characterized by chronic inflammation with extensive synovitis. RA starts by preclinical autoimmunity in a geneticallypredisposed person and progresses to the clinical appearance of articular cartilage erosion 
or marginal bone erosions, that result in joint destruction. ${ }^{1}$ The genetic and environmental factors are associated with the risk for RA development. In the pre-clinical stage, determination of these factors with clinical parameter could potentially be used to predict the RA disease development. ${ }^{2}$

Interleukin 16 (IL-16) is an inflammatory cytokine, formed by lymphocytes and also epithelial cells, and is working as a chemoattractant for various immunological cells like CD4+ cells, monocytes and eosinophils. IL-16 can also stimulate IL-2 receptor synthesis and induce expression of HLA-DR. ${ }^{3}$

In RA the induced IL-16 may play a role in initiating, sustaining and increasing the inflammatory response and development of synovitis by recruiting many inflammatory cells, including $T$ cells into synovial tissues, nevertheless IL-16's actual role in RA pathogenesis must be studied further. ${ }^{4}$

The IL-16 gene polymorphisms may influence and impact on the expression and secretion of IL-16 protein in the blood, which further result in relevant biological responses ${ }^{5}$. Several studies demonstrated that IL-16 gene polymorphisms play a crucial role in the pathogenesis of various diseases, such as osteoporosis, renal cell cancer, Alzheimer's disease and systemic lupus erythematosus $(\mathrm{SLE})^{5-8}$

The IL-16 gene encoding is at $15 q 26.1$ in chromosome 15. The most common SNP of IL16 polymorphism is $-295 \mathrm{~T} / \mathrm{C}$, which has been shown to cause decreased promoter activity in patients with asthma. The relation between unique variants of three SNPs, including the rs11556218 G allele, $-285 \mathrm{C}$ and rs4072111 T allele, and the increased risk of SLE has also been shown. ${ }^{5,9}$

IL-16 gene rs11556218 T/G is one of the most-studied SNPs. Previous studies showed a close relation and association with the onset of some human diseases, for example SLE, cancers, osteoporosis, coronary artery disease, and osteoarthritis. ${ }^{6,-11}$ The genetic polymorphisms reported in DNA sequence of IL-16 gene, could lead to cytokines production and activity. Therefore, IL-16 polymorphisms were analyzed and have association with autoimmune diseases. ${ }^{12}$ However, the association of IL-16 gene polymorphisms and RA disease susceptibility has not been examined and there are no data about the role of IL-16 polymorphism in risk of RA disease development.

Consequently, this case-control study aimed to investigate the association of IL-16 gene polymorphism and RA disease, to determine the genetic role of IL-16 polymorphism and predict the risk of RA development and clinical disease activity.

\section{Patients and Methods}

This is a case-control study. Patients with RA, according to the American College of Rheumatology/European League Against Rheumatism (ACR/EULAR) criteria of 2010, were recruited from the rheumatology clinics at Suez Canal university hospital, Ismailia, Egypt. The study included 150 RA patients and 150 volunteers as control subjects. The number of the study patients was calculated with $95 \%$ power (confidential level) to detect a common variant and minor allele frequency (MAF) is more than $10 \%$ and RA global prevalence ranged $0.25-1 \% .{ }^{13}$ The age and gender were matched in both groups. All patients were subjected to full medical history and clinical examination. Subjects with other connective tissue diseases including systemic lupus erythematosus, systemic sclerosis, dermatomyositis, or interstitial lung disease were excluded from the study. Similarly, cases with medical history of chronic infection including viral hepatitis or human immunodeficiency virus were also excluded. The study protocol was reviewed and approved by the Ethical Committee of the Suez Canal University (14/December 2018). An informed consent was signed by all study participants.

\section{$R A$ disease activity assessments}

Disease activity in RA cannot be assessed in all different patients according to a single variable tool so we used the following to measure the accurate patient's activity status: Disease Activity Score with 28-joint counts (DAS28) (erythrocyte sedimentation rate or C-reactive protein) (DAS28/ESR) or (DAS28/CRP) ${ }^{14}$ Clinical 
Disease Activity Index (CDAI) ${ }^{15}$ and Rheumatoid Arthritis Disease Activity Index-5 (RADAS-5). ${ }^{16}$

\section{Evaluation of RA functional status}

A Health Assessment Questionnaire-Disability Index (HAQ) was used to assess functional ability in RA patients. ${ }^{17}$

\section{Laboratory investigations}

These included erythrocyte sedimentation rate (ESR), carried out by using the Westergren method. C - reactive protein (CRP), Rheumatoid Factor (RF) and serum Anti- CCP were assessed by a fully automated immunoassay analyzer (COBAS e411 Roche diagnostics, Germany), according to the manufacturer's instructions.

\section{Assessment of Genotyping of IL-16 (SNP rs11556218 T/G)}

\section{Genomic DNA extraction:}

DNA from $200 \mathrm{ul}$ of whole blood was extracted using a commercially spin-column technique kit for genomic DNA extraction (Invitrogen PureLink Genomic DNA Mini Kit), according to the manufacturer's instructions. The eluted DNA from each sample was stored at $-20^{\circ} \mathrm{C}$ until used. The DNA purity was assessed by applying $1 \mu l$ to the NanoDrop spectrophotometer machine (Thermo Fisher Scientific Inc. USA), according to the manufacturer's instructions.

\section{SNP rs11556218 T/G Genotyping:}

IL-16 gene polymorphism (SNP rs11556218 T/G) was genotyped using a real-time polymerase chain reaction instrument (Bio-Rad, Applied Biosystems, Germany). Two sequence specific primers and two probes were used. The forward primer was: 5'- GCTCAGGTTCACAGAGTGTTTCC ATA $-3^{\prime}$ and the reverse primer: 5' TGTGACAAT
CACAGCTTGCCTG $-3^{\prime}$. Two TaqMan ${ }^{\circledR}$ MGB probes were used: one probe (VIC) to detect allele $T$ sequence and the other (FAM) to detect allele $\mathrm{G}$ sequence. Interpretation of the results was carried out through the allelic discrimination assay, a multiplexed, end-point assay, that detects the genotyping of single nucleotide polymorphism. Homozygous allele $T$ was detected on $\mathrm{X}$ axis on the plot. Homozygous allele $\mathrm{G}$ was detected on $\mathrm{y}$ axis on the plot and heterozygous Alleles $\mathrm{T}$ and $\mathrm{G}$ were detected in both axis on the plot.

\section{Statistical analysis}

The data were analyzed by SPSS 25 software and presented as frequencies and percentage or mean and standard deviation. Chi-square, t-test and ANOVA tests were used to compare between different studied variables. Regression analysis and Odds Ratio were evaluated to assess the ability of IL-16 polymorphism to predict RA disease. Hardy-Weinberg equilibrium was performed to assess the deviation in the genotype frequency of IL-16 (rs11556218) polymorphism. Hardy-Weinberg equilibrium was tested with the chi-square test to compare the observed genotype frequencies among studied RA patients and healthy controls with the expected genotype frequencies. The significance level was set to 0.05 or $5 \%$.

\section{Results}

In this study the mean age of RA patients and the control subjects were $46.32 \pm 6.12$ years and $47.63 \pm 4.05$ years, respectively. Males represented $26.7 \%$ and $25.3 \%$ of the RA patients and controls, respectively. Clinical and laboratory data of the RA patients are listed in Table 1. 
Table 1. Demographic, clinical data, and laboratory test results of the studied samples.

\begin{tabular}{lccccc} 
& \multicolumn{2}{c}{ RA patients $(\mathrm{n}=150)$} & \multicolumn{2}{c}{ Controls $(\mathrm{n}=150)$} & P-value \\
\cline { 2 - 4 } & No. & $\%$ & No. & $\%$ & \\
\hline Gender & 40 & $(26.7 \%)$ & 38 & $(25.3 \%)$ & NS \\
Male & 110 & $(73.3 \%)$ & 112 & $(74.7 \%)$ & \\
\cline { 2 - 4 } Female & & & &
\end{tabular}

Age (years)

Mean \pm SD.

$46.32 \pm 6.12$

$47.63 \pm 4.05$

NS

Disease duration

Mean \pm SD.

$2.83 \pm 0.87$

DAS/ESR

Mean \pm SD

$5.71 \pm 1.15$

DAS/CRP

Mean \pm SD

$4.42 \pm 0.95$

ESR (mm/hours)

Mean \pm SD

$59.23 \pm 23.71$

$\mathrm{CRP}(\mathrm{mg} / \mathrm{l})$

Mean \pm SD

$3.25 \pm 1.84$

$\mathrm{RF}(\mathrm{IU} \backslash \mathrm{ml})$

Mean \pm SD

$70.35 \pm 42.11$

Anti-CCP (U/ml)

Mean \pm SD

$151.8 \pm 89.2$

DAS: Disease Activity Score; CRP: C-reactive protein; ESR: Erythrocyte Sedimentation Rate; RF: Rheumatoid Factor Anti CCP: Anti Cyclic Citrullinated Peptide. P>0.05 is not significant (NS).

IL-16 (rs11556218 T/G) genotype frequencies of G/G were $5 / 150$ (3.3\%) in RA patients and 2/150 $(1.3 \%)$ in the control group. While the $\mathrm{G} / \mathrm{T}$ genotype was $33 / 150(22 \%)$ in RA patients and $24 / 150(16.0 \%)$ in the control group, the genotype $T / T$ was $112 / 150(74.7 \%)$ in $R A$ patients and $124 / 150(82.7 \%)$ in the control group. Although the genotypes results were adjusted with age and sex, the genotypes difference between RA patients and controls did not reach statistical significance $(P=0.19)$.

Allele $\mathrm{G}$ was present in $12.0 \%$ of RA patients and $9.0 \%$ of controls. T allele was present in $82.0 \%$ of RA patients and $91.0 \%$ of controls.
Interestingly, after the allele results were adjusted with age and sex, the allele differences between RA patients and controls were statistically significant $(P=0.047)$ as the $G$ allele was frequently presented in RA patients. Consequently, logistic regression analysis revealed that $G$ allele carriers have two times more risk to develop RA disease than $\mathrm{T}$ allele carriers (OR=2.598; 95\% Cl=1.078-6.825), Table 2. Genetic models association of IL-16 polymorphism ( $r s 11556218 \mathrm{~T} / \mathrm{G}$ ) in RA diseases confirmed that the presence of $G$ allele under the dominant model was a predictive factor to develop RA disease, Table 3. 
Table 2. IL-16 polymorphism ( $r(11556218 \mathrm{~T} / \mathrm{G}$ ) genotypes and allele frequencies with Logistic regression analysis to predict RA disease.

\begin{tabular}{|c|c|c|c|c|c|c|}
\hline $\begin{array}{l}\text { IL-16 } \\
\text { polymorphism } \\
\text { (rs11556218 T/G) }\end{array}$ & $\begin{array}{l}\text { RA patients } \\
\quad(n=150)\end{array}$ & $\begin{array}{l}\text { Healthy } \\
\text { Control } \\
(n=150)\end{array}$ & $\begin{array}{l}{ }^{*} P- \\
\text { value }\end{array}$ & OR $(95 \% \mathrm{Cl})$ & $\begin{array}{c}\text { \#adjusted } \\
P \text {-value }\end{array}$ & *OR $(95 \% \mathrm{Cl})$ \\
\hline $\mathrm{T} / \mathrm{T}$ & $112(74.7 \%)$ & $124(82.7 \%)$ & & 1.00 & & 1.00 \\
\hline $\mathrm{G} / \mathrm{T}$ & $33(22 \%)$ & $24(16 \%)$ & NS & $1.52(0.85-2.73)$ & NS & $1.82(0.89-3.95)$ \\
\hline $\mathrm{G} / \mathrm{G}$ & $5(3.3 \%)$ & $2(1.3 \%)$ & & $2.77(0.53-14.55)$ & & $2.98(0.52-14.74)$ \\
\hline \multicolumn{7}{|l|}{ Allele } \\
\hline $\mathrm{T}$ & 257 (88\%) & $272(91 \%)$ & & 1.00 & & 1.00 \\
\hline G & $43(12 \%)$ & $28(9 \%)$ & NS & $\begin{array}{c}1.625(0.980- \\
2.694)\end{array}$ & 0.047 & $\begin{array}{c}2.598(1.078- \\
6.825)\end{array}$ \\
\hline
\end{tabular}

$\mathrm{OR}=$ Odds ratio; $\mathrm{Cl}=$ Confidence interval \#Adjusted with sex and age. ${ }^{*} P>0.05$ is not significant (NS).

Table 3. Genetic models association of IL-16 polymorphism (rs11556218 T/G) in RA diseases.

\begin{tabular}{|c|c|c|c|c|c|c|c|}
\hline $\begin{array}{l}\text { Genetic } \\
\text { model }\end{array}$ & Genotypes & $\begin{array}{l}\text { Healthy } \\
\text { control } \\
(n=150)\end{array}$ & $\begin{array}{c}\text { RA } \\
\text { patient } \\
(n=150)\end{array}$ & OR $(95 \% \mathrm{Cl})$ & $\begin{array}{l}{ }^{*} P_{-} \\
\text {value }\end{array}$ & $\begin{array}{l}\text { Adjusted OR } \\
(95 \% \mathrm{Cl})\end{array}$ & $\begin{array}{c}\text { Adjusted } \\
p \text {-value }\end{array}$ \\
\hline \multirow{2}{*}{ Dominant } & $\mathrm{T} / \mathrm{T}$ & $\begin{array}{c}124 \\
(82.7 \%)\end{array}$ & $\begin{array}{c}112 \\
(74.7 \%)\end{array}$ & 1.00 & \multirow{2}{*}{ NS } & 1.00 & \multirow{2}{*}{0.05} \\
\hline & $\mathrm{G} / \mathrm{T}-\mathrm{G} / \mathrm{G}$ & $\begin{array}{c}26 \\
(17.3 \%)\end{array}$ & $\begin{array}{c}38 \\
(25.3 \%)\end{array}$ & $\begin{array}{c}1.62 \\
(0.92-2.83)\end{array}$ & & $\begin{array}{c}1.81 \\
(1.05-3.69)\end{array}$ & \\
\hline \multirow{2}{*}{ Recessive } & $\mathrm{T} / \mathrm{T}-\mathrm{G} / \mathrm{T}$ & $\begin{array}{c}148 \\
(98.7 \%)\end{array}$ & $\begin{array}{c}145 \\
(96.7 \%)\end{array}$ & 1.00 & \multirow{2}{*}{ NS } & 1.00 & \multirow{2}{*}{ NS } \\
\hline & $\mathrm{G} / \mathrm{G}$ & 2 (1.3\%) & $\begin{array}{c}5 \\
(3.3 \%)\end{array}$ & $\begin{array}{c}2.55 \\
(0.49-13.36)\end{array}$ & & $\begin{array}{c}2.68 \\
(0.58-15.31)\end{array}$ & \\
\hline \multirow{2}{*}{$\begin{array}{l}\text { Over } \\
\text { dominant }\end{array}$} & $\mathrm{T} / \mathrm{T}-\mathrm{G} / \mathrm{G}$ & 126 (84\%) & $\begin{array}{c}117 \\
(78 \%)\end{array}$ & 1.00 & \multirow{2}{*}{ NS } & 1.00 & \multirow{2}{*}{ NS } \\
\hline & $\mathrm{G} / \mathrm{T}$ & 24 (16\%) & $\begin{array}{c}33 \\
(22 \%)\end{array}$ & $\begin{array}{c}1.48(0.83- \\
2.65)\end{array}$ & & $\begin{array}{c}1.57 \\
(0.86-2.86)\end{array}$ & \\
\hline
\end{tabular}

${ }^{*} P>0.05$ is not significant (NS).

Moreover, relationship between IL 16 (rs11556218 T/G) genotype and allele frequencies with disease activity assessments and functional status in the RA patients was evaluated. There was a statistically significant difference between genotypes and CDAI and RADAS-5 ( $p=0.036 ; p=0.003$, respectively). Whereas, the $G / G$ genotype was associated with high CDAl and RADAS-5 levels and so associated with high clinical disease activity in comparison to other genotypes (T/T-T/G). Furthermore, there was a statistically significant difference between genotypes and HAQ $(p=0.015)$, and also the $G / G$ genotype associated with increase in the HAQ disability index levels in comparison to other genotypes ( $T / T-T / G)$. On the other hand, there was no statistically significant difference between both alleles and any of disease activity assessments or functional status in the RA patients, Table 4. 
Table 4. Relation between IL 16 ( $r$ s11556218 T/G) genotype and allele frequencies with disease activity assessments and functional status in the RA patients.

\begin{tabular}{|c|c|c|c|c|c|c|c|}
\hline & \multicolumn{3}{|c|}{ IL-16 genotypes } & \multirow{2}{*}{$\begin{array}{c}* P \text { - } \\
\text { value }\end{array}$} & \multicolumn{2}{|c|}{ IL-16 alleles } & \multirow{2}{*}{$\begin{array}{c}{ }^{*} P_{-} \\
\text {value }\end{array}$} \\
\hline & $\mathrm{G} / \mathrm{G}(\mathrm{n}=5)$ & $T / G(n=33)$ & $T / T(n=112)$ & & $\begin{array}{l}\text { G allele } \\
(n=43)\end{array}$ & $\begin{array}{c}\text { Tallele } \\
(n=257)\end{array}$ & \\
\hline $\begin{array}{l}\text { DAS/ESR } \\
\text { Mean } \pm \text { SD }\end{array}$ & $6.21 \pm 0.57$ & $5.36 \pm 0.87$ & $5.91 \pm 1.15$ & NS & $5.99 \pm 0.91$ & $5.94 \pm 1.15$ & NS \\
\hline$\overline{D A S / C R P}$ & & & & & & & \\
\hline Mean \pm SD & $4.79 \pm 0.51$ & $4.25 \pm 0.84$ & $4.61 \pm 0.94$ & NS & $4.46 \pm 0.91$ & $4.59 \pm 0.95$ & NS \\
\hline CDAI & & & & & & & \\
\hline Mean \pm SD & $38.0 \pm 1.2$ & $21.66 \pm 9.2$ & $27.67 \pm 10.54$ & 0.036 & $27.11 \pm 10.86$ & $26.79 \pm 10.46$ & NS \\
\hline $\begin{array}{l}\text { RADAS-5 } \\
\text { Mean } \pm \text { SD }\end{array}$ & $6.08 \pm 0.15$ & $4.06 \pm 0.80$ & $4.64 \pm 0.91$ & 0.003 & $4.73 \pm 1.17$ & $4.55 \pm 0.90$ & NS \\
\hline $\begin{array}{l}\mathrm{HAQ} \\
\text { Mean } \pm \text { SD }\end{array}$ & $2.30 \pm 0.1$ & $1.50 \pm 0.47$ & $1.68 \pm 0.39$ & 0.015 & $1.66 \pm 0.45$ & $1.65 \pm 0.40$ & NS \\
\hline
\end{tabular}

\section{Discussion}

Many cytokines are presented in RA patient's joints. It is evident that these cytokines have a major role to play in processes that cause inflammation, joint damage and RA-related comorbidities. Afterward the achievement of the TNF- $\alpha$ blockade in RA therapy, other cytokines provide alternative goals or may be helpful as predictor biomarkers of the RA disease. ${ }^{18}$ The cytokine, IL-16, stimulates the expression and production of many proinflammatory cytokines and might play a significant role in the pathogenesis of chronic inflammation, disease process and joint destruction in RA disease. ${ }^{19-21}$

According to this study results, there was no statistically significant association of IL-16 genotypes ( $r$ 11556218 T/G) with susceptibility of RA disease however patients carrying the $G$ allele had two times higher risk for developing RA disease than $T$ allele carriers as well as the G/G genotype associated with increased clinical disease activity and health disability. To the best of our knowledge, this is the first study to identify the relation of IL-16 polymorphism ( $r s 11556218 \mathrm{~T} / \mathrm{G}$ ) with RA disease in Egypt.

Some previous studies reported IL-16 polymorphism in relation to other diseases. For instance, a study by Zhang et al., 2020 reported that there was no genetic association of IL-16 gene rs11556218 SNP with the risk of Parkinson's disease in a Chinese Han population. ${ }^{22}$ Another report by Xue et al., 2009 performed a study among 138 SLE patients and 199 controls to determine whether the polymorphisms of IL-16 gene contribute to the risk for SLE in a Chinese population. They reported some associations between both allele and genotype frequencies of the $\mathrm{rs} 4072111 \mathrm{C} / \mathrm{T}$, rs4778889 T/C, and rs11556218 T>G SNPs and risk of SLE. ${ }^{9}$

In another study, Cheng et al., 2019 investigated 133 type 2 diabetes mellitus (T2DM) patients and 127 controls and explored the significant genetic association of IL-16 gene rs11556218 SNP with T2DM susceptibility in a Chinese Han population. ${ }^{5}$ They reported that G allele frequencies of rs11556218 increased remarkably in the case group more than that in controls and so also associated with an increased risk of T2DM (OR $=1.639,95 \% \mathrm{Cl}=$ 1.087-2.471)..$^{5}$

In the current study, there was a significant association between IL-16 genotype G/G and disease activity and health disability. In spite of that the functional role of IL-16 as an 
inflammatory mediator is quiet unclear. However, there are evidence that IL-16 contributes in the inflammatory disorder via the stimulation and activation of T Iymphocytes and the secretion of many inflammatory cytokines which may lead to synovitis and progress to joint destruction and disability. ${ }^{23,24}$

In conclusion, we observed an association between allele $\mathrm{G}$ of IL-16 polymorphism (rs11556218 T/G) and risk of RA disease development. Similarly, there was an association between IL-16 polymorphism (rs11556218 T/G) genotype G/G and increase clinical disease activity levels and health disability.

\section{Author Contributions}

$\mathrm{SM}$; prepare the study design, samples collection, assemble the data, analysis and interpretation of study data and final adjustment and revision. SN; design of the study, select the participants, interpretation of data, and final approval. $\mathrm{AH}$; put the study plan, interpret the data, editing and final revision. $\mathrm{AA}$; acquisition of data, interpret and analyze the data, drafting the article and final revision. $\mathrm{HO}$; formulate the idea and design the proposal, analysis of the data, editing and final revision and approval.

\section{Declaration of Conflicting Interests}

The author(s) declared no potential conflicts of interest with respect to the research, authorship, and/or publication of this article.

\section{Funding}

The author(s) denies receipt of any financial support for the research, authorship, and/or publication of this article.

\section{Ethical approval}

The study protocol was reviewed and approved by the Ethical Committee of the Suez Canal University (14/December 2018). An informed consent was signed by all study participants.

\section{Informed consent}

An informed consent was signed by all study participants.

\section{References}

1. Zordan P, Rigamonti E, Freudenberg $K$, et al. (2014). Macrophages commit postnatal endothelium-derived progenitors to angiogenesis and restrict endothelial to mesenchymal transition during muscle regeneration. Cell death \& disease. 5(1):e1031.

2. Deane KD, El-Gabalawy H. (2014). Pathogenesis and prevention of rheumatic disease: focus on preclinical RA and SLE. Nature reviews Rheumatology. 10(4):212-28.

3. Akdis M, Burgler S, Crameri R, et al. (2011). Interleukins, from 1 to 37 , and interferon- $\gamma$ : receptors, functions, and roles in diseases. The Journal of allergy and clinical immunology. 127(3):701-21.e1-70.

4. Cho M-L, Jung YO, Kim K-W, et al. (2008). IL-17 induces the production of IL-16 in rheumatoid arthritis. Experimental \& molecular medicine. 40(2):237-45.

5. Cheng F, Liu L, Zhang $H$, et al. (2019). Association of IL-16 gene polymorphisms with the risk of developing type 2 diabetes mellitus in the Chinese Han population. Bioscience Reports. 39(8).

6. Ma X, Chen Y, Zhang Q, et al. (2017). Interleukin16 rs11556218 is associated with a risk of osteoporosis in Chinese postmenopausal women. Eur J Obstet Gynecol Reprod Biol. 210:90-3.

7. Khoshbakht $T$, Soosanabadi $M$, Neishaboury $M$, et al. (2015). An Association Study on IL16 Gene Polymorphisms with the Risk of Sporadic Alzheimer's Disease. Avicenna journal of medical biotechnology. 7(3):128-32.

8. Yang S, Chen F, Zhang J, et al. 2016 IL-16 rs4778889 polymorphism contribution to the development of renal cell cancer in a Chinese population. Genet Mol Res.15(2).

9. Xue H, Gao L, Wu Y, et al. (2009). The IL-16 gene polymorphisms and the risk of the systemic lupus erythematosus. Clinica chimica acta; international journal of clinical chemistry. 403(1-2):223-5.

10. Hai-Feng T, Wei W, Yuan-Yuan Y, et al. (2013). Association between Polymorphisms in IL-16 Genes and Coronary Heart Disease risk. Pakistan journal of medical sciences. 29(4):1033-7.

11. Luo SX, Li S, Zhang XH, et al. (2015). Genetic polymorphisms of interleukin-16 and risk of knee osteoarthritis. PloS one. 10(5):e0123442.

12. Karkhane M, Mohebbi SR, Azimzadeh P, et al. (2018). Genetic association between a single nucleotide polymorphism in Interleukin-16 (rs4072111) and susceptibility to chronic HCV 
infection in an Iranian population. Gastroenterol Hepatol Bed Bench. 11(1):42-7.

13. Almoallim H, Al Saleh J, Badsha H, et al. (2021). A Review of the Prevalence and Unmet Needs in the Management of Rheumatoid Arthritis in Africa and the Middle East. Rheumatology and Therapy. 8(1):116.

14. van Riel PL, Renskers L. (2016). The Disease Activity Score (DAS) and the Disease Activity Score using 28 joint counts (DAS28) in the management of rheumatoid arthritis. Clinical and experimental rheumatology.34(5 Suppl 101):S40-s4.

15. Singh $H$, Kumar $H$, Handa R, et al. (2011). Use of clinical disease activity index score for assessment of disease activity in rheumatoid arthritis patients: an Indian experience. Arthritis. 2011:146398-.

16. Sunar I, Yilmaz Tasdelen O, Garip Cimen Y, et al. (2017). Translation and validation of the Turkish language version of the Rheumatoid Arthritis Disease Activity Index-5. International journal of rheumatic diseases.20(12):2012-9.

17. Maska L, Anderson J, Michaud K. (2011). Measures of functional status and quality of life in rheumatoid arthritis: Health Assessment Questionnaire Disability Index (HAQ), Modified Health Assessment Questionnaire (MHAQ), Multidimensional Health Assessment Questionnaire (MDHAQ), Health Assessment Questionnaire II (HAQII), Improved Health Assessment Questionnaire (Improved HAQ), and Rheumatoid Arthritis Quality of
Life (RAQoL). Arthritis care \& research. 63 Suppl 11:S4-13.

18. Siebert S, Tsoukas A, Robertson J, et al. (2015). Cytokines as therapeutic targets in rheumatoid arthritis and other inflammatory diseases. Pharmacological reviews. 67(2):280-309.

19. Lard LR, Roep BO, Toes RE, et al. (2004). Enhanced concentrations of interleukin 16 are associated with joint destruction in patients with rheumatoid arthritis. The Journal of rheumatology. 31(1):35-9.

20. Dembic Z. (2015). The cytokines of the immune system: the role of cytokines in disease related to immune response: Academic Press; 2015.

21. Li Y, Wang Z, Yu T, et al. (2014). Increased expression of IL-37 in patients with Graves' disease and its contribution to suppression of proinflammatory cytokines production in peripheral blood mononuclear cells. PloS one.9(9):e107183.

22. Zhang X, Xue L, Sun X, et al. (2020). Association of IL-16 gene polymorphisms with sporadic Parkinson's disease in a Han Chinese population. Neuroscience letters.724:134877.

23. Brait VH, Arumugam TV, Drummond GR, et al. (2012). Importance of T lymphocytes in brain injury, immunodeficiency, and recovery after cerebral ischemia. J Cereb Blood Flow Metab. 32(4):598-611.

24. Kleinschnitz C, Kraft P, Dreykluft A, et al. (2013). Regulatory $T$ cells are strong promoters of acute ischemic stroke in mice by inducing dysfunction of the cerebral microvasculature. blood. 121(4):679-91. 